\title{
Disentangling the dynamics of invasive fireweed (Senecio madagascariensis Poir. species complex) in the Hawaiian Islands
}

\section{Johannes J. Le Roux}

Department of Tropical Plant and Soil Sciences, University of Hawaii at Manoa, 3190 Maile Way, St. John 102, Honolulu, HI 96822, USA

Department of Botany and Zoology, Centre of Excellence for Invasion Biology, Stellenbosch University, Natural Sciences Building, Matieland, 7602, South Africa

\section{Ania M. Wieczorek}

Department of Tropical Plant and Soil Sciences, University of Hawaii at Manoa, 3190 Maile Way, St. John 102, Honolulu, HI 96822, USA

\section{Carol T. Tran}

Department of Tropical Plant and Soil Sciences, University of Hawaii at Manoa, 3190 Maile Way, St. John 102, Honolulu, HI 96822, USA

Adam E. Vorsino

Department of Plant and Environmental Protection Sciences, University of Hawaii at Manoa, 3050 Maile Way, Gilmore 310, Honolulu, HI 96822, USA

\begin{abstract}
Studies investigating the genetic variation of invasive species render opportunities to better understand the dynamics of biological invasions from an ecological and evolutionary perspective. In this study, we investigate fine-scale population genetic structure of invasive Senecio madagascariensis (fireweed) using microsatellite markers to determine levels of genetic diversity and how it pertains to introduction history of this species within and among the Hawaiian Islands. Dispersal patterns were interpreted and, together with a habitat suitability analysis, we aim to describe the potential range expansion of S. madgascariensis within the islands. Bayesian and frequency-based analyses revealed genetic structure with two major genetic demes corresponding to the two fireweed-infested islands of Maui and Hawaii. Both these demes showed further genetic sub-structure, each consisting of three genetically distinct subgroups. Overall, fireweed showed significant levels of inbreeding. Major genetic demes (Maui and Hawaii) differed in observed heterozygosities, inbreeding and genetic structure, each harbouring a large proportion of private alleles. In contrast to the current understanding of fireweed's introduction history between the Hawaiian Islands, fine-scale population genetic parameters suggest that this species has been introduced at least twice, possibly even more, to the archipelago. Spatial analyses also revealed high correlation between genetic similarity and geographical proximity ( $>2 \mathrm{~km}$ apart) followed by a sharp decline. In addition, a single population was identified that likely resulted from a rare human- or animal-mediated extreme longdistance dispersal event from Maui to Hawaii. Bayesian and likelihood estimates of 'first generation migrants' also concurred that contemporary dispersal occurs more frequently over smaller spatial scales than larger scales. These findings indicate that spread in this species occurs primarily via a stratified strategy. Predictions from habitat suitability models indicate all Hawaiian Islands as highly suitable for fireweed invasion and the movement of propagules to currently uninfested islands and outlying suitable habitats should be avoided to circumvent further expansions of the invasion.
\end{abstract}

Keywords: Population genetics; Senecio madagascariensis; Microsatellite; Genetic diversity; Stratified dispersal; Habitat suitability 


\section{Introduction}

Plant biological invasions are key factors leading to changes in the functioning of ecosystems, native species' biodiversity and in evolutionary trajectories of species (Vitousek 1990; Lee 2002; Strauss et al. 2006). Several attributes of successful plant invaders have been determined, such as release from herbivores and/or pathogens (Keane and Crawley 2002) and reproductive traits that overcome or mitigate partner and pollinator limitations (van Kleunen et al. 2007). However, generality on the characteristics typically associated with successful invasions is still largely lacking. Recent studies also emphasize the importance of evolutionary processes in invasion success (Lee 2002; Mooney and Cleland 2001; Sakai et al. 2001; Barrett et al. 2008; Rosenthal et al. 2008). This, in part, is because small founding populations often harbor limited genetic substrate for selection to act on in new environments, in many cases leading to establishment failure (Sakai et al. 2001). The amount of genetic variation in invasive populations will be influenced by the number and source of founders, drift, selection, dispersal and breeding system (Lee 2002; Barrett et al. 2008).

Phylogeographic and population genetic analyses can provide important insights into the dynamics of biological invasions by elucidating geographical source(s), dispersal route(s), spread and the roles of evolutionary processes in invasion success. This might help to lay foundations for a deeper understanding of the mechanisms underlying successful invasions (Le Roux and Wieczorek 2009). For instance, for taxonomically problematic invasive taxa, genetic data will be crucial to determine species identity and native provenance(s). Such data, in turn, will greatly enhance the efficiency of biological control programmes by identifying regions to seek for host-specific and co-evolved natural enemies (e.g. Goolsby et al. 2006). Furthermore, genetic studies can advance our understanding of complex patterns of postestablishment spread (Viard et al. 2006), in many instances, with direct management implications such as the identification of feasible eradication units (e.g. Robertson and Gemmell 2004).

Nevertheless, multidisciplinary research that combines information on the genetic structure of introduced species and their survival capacity under new environmental conditions would provide the most comprehensive understanding of the mechanisms underlying their success and to identify effective management. For example, knowing the dispersal pathways that explain the distribution of invasive populations might be of very little management value, especially under heterogeneous habitats, as range expansion ultimately depend on the availability of suitable habitat(s). Similarly, identifying suitable habitat alone would not guarantee establishment of a particular species if dispersal limitations prohibit propagules from reaching those habitats. Under these circumstances, approaches combining dispersal ability with the suitability of the environment provide more realistic estimates of the potential range expansions of species (Kearney and Porter 2009).

Here, we took an integrated approach to better understand the invasion dynamics of Senecio madagascariensis Poir. in the Hawaiian archipelago. Commonly known as fireweed, Madagascar fireweed or Madagascar ragwort, Senecio madagascariensis is a member of the Asteraceae family native to Madagascar, the Mascarene islands and Southern Africa and forms part of a taxonomically problematic species complex (Le Roux et al. 2006). It is a short-lived perennial herb but behaves most commonly as an annual (survival period $\leq 1$ year), growing strongly from autumn to spring (Sindel et al. 1998). Members of the S. madgascariensis species complex appear to have mixed mating systems (Lafuma and Maurice 2007), often showing high levels of self-compatibility (Ernst 1998). For example, in the absence of partners, outlying and isolated fireweed plants appear to be fully self-compatible (Curt Daehler, personal communication). Seed dispersal is mostly wind mediated, but animals and animal feed (human-mediated) may occasionally act as dispersal vectors (Sindel et al. 1998).

Fireweed is a serious pasture weed in numerous locations outside of its Afro-Madagascan native ranges (Le Roux et al. 2006). It has large distribution ranges in highland areas in Kenya and Colombia and areas in Argentina, Hawaii and south-eastern Australia. Accidentally introduced to the Hawaiian Islands in the early 1980's fireweed is now widely distributed on Hawaii and Maui (Motooka et al. 1999) where it is currently the target of a biological control programme (M. Ramadan, Hawaii Department of Agriculture, personal communication). It appears that fireweed reached the archipelago secondarily from Australia (Le Roux et al. 2006; Motooka et al. 1999) and that Hawaiian populations most closely resemble native populations from eastern South Africa (Le Roux et al. 2006).

In this study we compare the genetic diversity between individuals, populations of S. madagascariensis and different invaded islands. We aim to determine if $\mathrm{S}$. madagascariensis infestations represent one or multiple introductions and whether dispersal is primarily diffusive, long-distance, or a combination of both 
(stratified dispersal). Secondly, we use habitat suitability models to determine the extent of suitable areas for invasion and discuss our findings in the light of population genetic parameters.

\section{Materials and methods}

\section{Population sampling and DNA extraction}

Twenty-six populations of S. madagascariensis were collected from areas within its known distribution in the Hawaiian Islands (Hawaii and Maui) (Fig. 1). For each population, leaf material from 7-30 individual plants was collected. A population was defined as any community of fireweed plants (between 5-150 individuals) that was separated by at least two kilometres from any other population. Collected leaf material was kept on ice in the field for no longer than $24 \mathrm{~h}$ before being transferred to $\mathrm{a}-80^{\circ} \mathrm{C}$ freezer. Locality name, region, latitude, and longitude were recorded for all populations sampled. In total 694 individuals were sampled from 26 putative populations (Table 1 ).
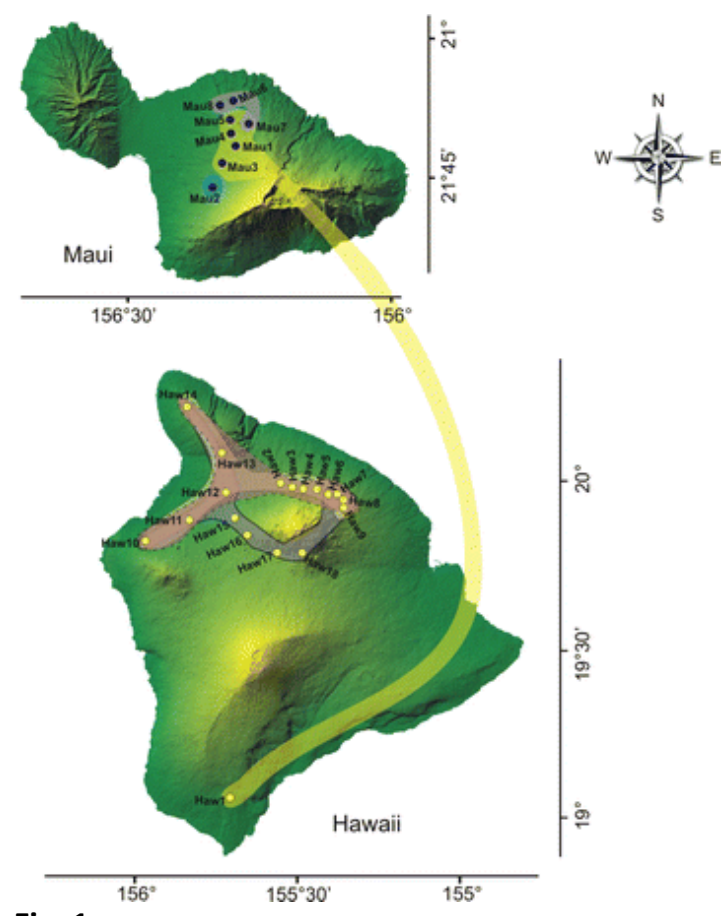

Fig. 1

Map of Maui and Hawaii indicating the locations of all populations of Senecio madgascariensis included in this study. Shaded polygons indicate sub-genetic groupings of individual populations identified by STRUCTURE analysis. Polygons are filled with colours that correspond to those used in Fig. $\underline{3}$ 
Table 1

Location and genetic diversity data for S. madagascariensis populations included in this study

\begin{tabular}{|c|c|c|c|c|c|c|c|c|}
\hline \multicolumn{4}{|c|}{ Location information } & \multicolumn{5}{|c|}{ Genetic diversity } \\
\hline ID & Region & Locality & Latitude/Longitude & $\mathbf{N}$ & A & $\mathrm{H}_{\mathrm{o}}$ & $\mathrm{H}_{\mathrm{E}}$ & $F_{\text {is }}$ \\
\hline \multicolumn{9}{|l|}{ Maui } \\
\hline Mau1 & Maui & Haleakela & N $20^{\circ} 84.374^{\prime} / \mathrm{W} 156^{\circ \prime} 33.806^{\prime}$ & 31 & 11.000 & 0.48 & 0.81 & 0.349 \\
\hline Mau2 & Maui & Kula & $\mathrm{N} 20^{\circ} 84.435^{\prime} / \mathrm{W} 156^{\circ \prime} 33.890^{\prime}$ & 29 & 7.250 & 0.41 & 0.74 & 0.382 \\
\hline Mau3 & Maui & Lower Kula & N $20^{\circ} 47.961^{\prime} / \mathrm{W} 156^{\circ} 19.624^{\prime}$ & 30 & 10.875 & 0.53 & 0.83 & 0.274 \\
\hline Mau4 & Maui & Haleakela & N $20^{\circ} 51.449^{\prime} / \mathrm{W} 156^{\circ} 21.570^{\prime}$ & 29 & 12.875 & 0.52 & 0.83 & 0.288 \\
\hline Mau5 & Maui & Makawao & $\mathrm{N} 20^{\circ} 51.173^{\prime} / \mathrm{W} 156^{\circ} 18.777^{\prime}$ & 7 & 4.750 & 0.47 & 0.81 & 0.263 \\
\hline Mau6 & Maui & Kokomo Rd & N $20^{\circ} 52.492^{\prime} / \mathrm{W} 156^{\circ} 18.894^{\prime}$ & 24 & 7.750 & 0.52 & 0.76 & 0.179 \\
\hline Mau7 & Maui & Waiohiwi falls & N $20^{\circ} 50.233^{\prime} / \mathrm{W} 156^{\circ} 16.802^{\prime}$ & 12 & 5.250 & 0.40 & 0.79 & 0.217 \\
\hline Mau8 & Maui & Baldwin and Halimaile & N $20^{\circ} 52.453^{\prime} / \mathrm{W} 156^{\circ} 19.809^{\prime}$ & 17 & 6.500 & 0.40 & 0.81 & 0.320 \\
\hline \multicolumn{9}{|l|}{ Hawaii } \\
\hline Haw1 & Hawaii & Kahuku ranch & N $19^{\circ} 11.117^{\prime} / \mathrm{W} 155^{\circ} 67.596^{\prime}$ & 31 & 10.875 & 0.48 & 0.79 & 0.352 \\
\hline Haw2 & Hawaii & Makahalau & $\mathrm{N} 20^{\circ} 00.366^{\prime} / \mathrm{W} 155^{\circ} 35.632^{\prime}$ & 28 & 9.750 & 0.41 & 0.79 & 0.364 \\
\hline Haw3 & Hawaii & Mana Rd & $\mathrm{N} 19^{\circ} 59.121^{\prime} / \mathrm{W} 155^{\circ} 33.04^{\prime}$ & 30 & 10.000 & 0.42 & 0.77 & 0.393 \\
\hline Haw4 & Hawaii & Hanaipoe & N $19^{\circ} 57.602^{\prime} / \mathrm{W} 155^{\circ} 30.857^{\prime}$ & 29 & 9.750 & 0.40 & 0.79 & 0.445 \\
\hline Haw5 & Hawaii & Keanakolu Rd & N $19^{\circ} 56.758^{\prime} / \mathrm{W} 155^{\circ} 29.304^{\prime}$ & 30 & 10.250 & 0.46 & 0.80 & 0.326 \\
\hline Haw6 & Hawaii & Koholalele gulch & N $19^{\circ} 56.787^{\prime} / \mathrm{W} 155^{\circ} 24.987^{\prime}$ & 30 & 11.125 & 0.46 & 0.79 & 0.334 \\
\hline Haw7 & Hawaii & Parker ranch & N $19^{\circ} 55.389^{\prime} / \mathrm{W} 155^{\circ} 20.678^{\prime}$ & 30 & 7.375 & 0.34 & 0.72 & 0.438 \\
\hline Haw8 & Hawaii & Pu'u Lahohinu & $\mathrm{N} 19^{\circ} 54.436^{\prime} / \mathrm{W} 155^{\circ} 20.577^{\prime}$ & 29 & 8.875 & 0.37 & 0.74 & 0.432 \\
\hline Haw9 & Hawaii & Laupahoehoe forest reserve & N $19^{\circ} 56.109^{\prime} / \mathrm{W} 155^{\circ} 23.598^{\prime}$ & 30 & 8.625 & 0.41 & 0.79 & 0.396 \\
\hline Haw10 & Hawaii & Pu’u Alau’awa & N $19^{\circ} 46.665^{\prime} / \mathrm{W} 155^{\circ} 54.885^{\prime}$ & 28 & 9.250 & 0.40 & 0.77 & 0.389 \\
\hline Haw11 & Hawaii & Mamalahoa Hwy & $\mathrm{N} 19^{\circ} 50.502^{\prime} / \mathrm{W} 155^{\circ} 45.496^{\prime}$ & 29 & 10.250 & 0.46 & 0.80 & 0.391 \\
\hline Haw12 & Hawaii & Saddle Road Junction & $\mathrm{N} 19^{\circ} 57.468^{\prime} / \mathrm{W} 155^{\circ} 40.845^{\prime}$ & 30 & 10.000 & 0.43 & 0.81 & 0.390 \\
\hline Haw13 & Hawaii & Waimea & $\mathrm{N} 20^{\circ} 02.257^{\prime} / \mathrm{W} 155^{\circ} 42.716^{\prime}$ & 30 & 10.000 & 0.41 & 0.81 & 0.431 \\
\hline Haw14 & Hawaii & Pu'u Hue ranch & N $20^{\circ} 09.254^{\prime} / \mathrm{W} 155^{\circ} 48.722^{\prime}$ & 30 & 10.625 & 0.45 & 0.84 & 0.439 \\
\hline Haw15 & Hawaii & Waiki'I ranch & $\mathrm{N} 19^{\circ} 52.387^{\prime} / \mathrm{W} 155^{\circ} 39.572^{\prime}$ & 25 & 9.250 & 0.4 & 0.79 & 0.431 \\
\hline Haw16 & Hawaii & Pu’u La'au & $\mathrm{N} 19^{\circ} 47.649^{\prime} / \mathrm{W} 155^{\circ} 37.588^{\prime}$ & 30 & 9.125 & 0.42 & 0.78 & 0.399 \\
\hline Haw17 & Hawaii & Bradshaw Airfield & $\mathrm{N} 19^{\circ} 45.339^{\prime} / \mathrm{W} 155^{\circ} 32.829^{\prime}$ & 30 & 9.625 & 0.41 & 0.76 & 0.419 \\
\hline Haw18 & Hawaii & Humuula Trail & N $19^{\circ} 47.729^{\prime} / \mathrm{W} 155^{\circ} 27.390^{\prime}$ & 16 & 6.250 & 0.38 & 0.76 & 0.383 \\
\hline Average & & & & & 9.125 & 0.43 & 0.79 & 0.360 \\
\hline
\end{tabular}

Genetic data are given as sample sizes $(\mathrm{N})$, number of alleles per population $(\mathrm{A})$, average observed heterozygosity across loci $\left(\mathrm{H}_{\mathrm{O}}\right)$, expected heterozygosity $\left(\mathrm{H}_{\mathrm{E}}\right)$ and fixation index $\left(\mathrm{F}_{\text {is }}\right)$

Total genomic DNA was extracted according to the manufacturer's protocol with the Wizard genomic DNA purification kit (Promega) from 40 to $50 \mathrm{mg}$ leaf material that was frozen in liquid nitrogen and ground by hand. All extractions were stored at $-80^{\circ} \mathrm{C}$.

\section{Microsatellite analysis}

Details concerning the isolation, characterization, and internal repeat structure of the $\mathrm{S}$. madagascariensis microsatellite loci used in this study can be found in Le Roux and Wieczorek (2006). Two loci, Se-206 and Se-46, were excluded from all analysis due to excessive failure in individuals that successfully amplified all other loci (i.e. null alleles), resulting in a total of only eight loci scored across all individuals. Polymerase chain reaction (PCR) amplification of loci was done in $10 \mu \mathrm{L}$ volumes with the Qiagen Multiplex PCR Kit (Qiagen) by combining primer pairs into two different multiplex reactions. Each PCR reaction contained $5 \mu \mathrm{L} 2$ X Qiagen Multiplex PCR Mastermix [HotStarTaq DNA Polymerase; Qiagen Multiplex PCR Buffer (6 mM 
$\mathrm{MgCl}_{2}, \mathrm{pH}$ 8.7); dNTP mix], $1 \mu \mathrm{L}$ 10X primer mix (see supplementary material), $1 \mu \mathrm{L}$ Q-solution [PCR additive(Qiagen)] and approximately $5 \mathrm{ng}$ total genomic DNA. All reactions followed a thermal cycle consisting of an initial denaturation at $95^{\circ} \mathrm{C}$ for $15 \mathrm{~min}$, followed by 35 cycles at $94^{\circ} \mathrm{C}$ for $60 \mathrm{~s}$, annealing at $55^{\circ} \mathrm{C}$ (multiplex 1) or $60^{\circ} \mathrm{C}$ (multiplex 2) for $60 \mathrm{~s}$, elongation at $72^{\circ} \mathrm{C}$ for $90 \mathrm{~s}$, and final extension at $72^{\circ}$ for 30 min. Polymorphisms were screened using an ABI PRISM 377XL DNA sequencer (PE Applied Biosystems) and PCR products sized relative to the LIZ500 molecular size marker (PE Applied Biosystems). Gel analysis and scoring of genotypes was done using the GeneMarker version 1.4 programme (SoftGenetics, LLC).

\section{Genetic diversity}

The number of alleles was calculated for each population using GenAlEx6 (Peakall and Smouse 2006), and observed $\left(\mathrm{H}_{\mathrm{O}}\right)$ and expected $\left(\mathrm{H}_{\mathrm{E}}\right)$ heterozygosities, deviations of genotype frequencies from those expected under Hardy-Weinberg equilibrium (HWE) and linkage disequilibrium among all pairs of loci were estimated using Arlequin version 3.01 (Schneider et al. 2000). For HWE, a Monte Carlo approximation of the Fisher's exact test was used (Guo and Thompson 1992) and a standard Bonferroni correction for multiple comparisons where the Markov chain algorithm was run for 100,000 steps following 10,000 dememorization steps.

\section{Population structure}

Pairwise $\mathrm{F}_{\mathrm{st}}$ and inbreeding coefficient $\left(\mathrm{F}_{\text {is }}\right)$ values were estimated using Arlequin version 3.01 (Schneider et al. 2000) and FSTAT293 (Goudet 2001) respectively. An analysis of molecular variance (AMOVA, Excoffier et al. 1992) was used to examine the distribution of genetic variation at three hierarchical levels: within populations, among populations within islands, and among islands. This test partitions total genetic variance into covariance components and calculates fixation indices (Wright 1965) for which statistical significance is determined by comparison with a null distribution derived from permuting haplotypes, individuals or populations at the appropriate hierarchical level (Excoffier et al. 1992). Statistical comparisons of genetic diversity parameters between the islands (i.e. Hawaii and Maui populations) included, allelic richness $\left[\mathrm{R}_{\mathrm{s}}\right]$, unbiased gene diversity $\left[\mathrm{H}_{s}\right]$, observed heterozygosity $\left[\mathrm{H}_{\mathrm{o}}\right]$, inbreeding coefficient $\left[F_{\text {IS }}\right]$ and levels of differentiation among populations $\left[F_{S T}\right]$ and were performed with FSTAT293 (Goudet 2001).

To test for isolation by distance, Mantel tests with 1000 permutations as implemented in IBDWS V2 were used (Jensen et al. 2005). A matrix of pairwise log-transformed $F_{S T}$ values was tested against a matrix of log-transformed geographical distances.

To test for population structure among populations throughout Hawaii and to assess the geographical scale of population differentiation, we used a fully Bayesian approach implemented in STRUCTURE version 2.2 (Falush et al. 2007) and the partial Bayesian method (Rannala and Mountain 1997) implemented in GeneClass2 (Piry et al. 2004). For the STRUCTURE analysis a series of pilot runs were used to estimate $\operatorname{Pr}(X \mid K)$, where $X$ represents the data, for $K$ between 1 (the expected value if all populations represent a single panmictic unit) and 26 (the maximum number of populations). Using the options to ignore population affiliation when defining genetic clusters, assuming independence among loci, and allowing admixture, four independent runs of 300,000 iterations were done, following a burn-in period of 100,000, for each value of K (Pritchard et al. 2000). We also calculated $\Delta \mathrm{K}$ (Evanno et al. 2005) for our data by taking into account the shape of the log-likelihood curve with increasing $K$ and variance among estimates among multiple runs. Once the number of genetic clusters was established, each individual was assigned to the genetic group for which its inferred ancestry was the highest, provided this value was higher than 0.6 (i.e. more than half of the individual's genome is assigned to the same genetic group). Simulations from previous studies indicate that the methods described above only detect the uppermost level of genetic structure (Evanno et al. 2005). We therefore used a hierarchical approach (Coulon et al. 2008) to detect sub-levels of genetic structure. In short, we repeated the initial analyses (estimation of the number of groups with the $\Delta \mathrm{K}$ method and assignment of individuals to groups) on each of the $\mathrm{K}$ groups inferred in the previous step. In addition, we also assigned individual populations to a specific genetic group provided that more than $50 \%$ of its individuals were assigned to that genetic group. For the analysis in GeneClass2 (Piry et al. 2004), we ran 10,000 MCMC simulations per population (Paetkau et al. 2004) using the Lh/Lmax likelihood computation, where $\mathrm{Lh}$ is the likelihood of an individual being assigned to the population where it was sampled and Lmax is the maximum likelihood for all populations considered. We considered an 
individual to be a migrant if the Lh/Lmax $\mathrm{P}$ value was below 0.01 . Simulations have demonstrated that setting alpha values to this level maximizes accuracy and power (Paetkau et al. 2004).

\section{Global spatial autocorrelation analysis}

We used the spatial autocorrelation method of Smouse and Peakall (1999), as implemented in the software package GenAlEx (Peakall and Smouse 2006), to investigate the relationship between genetic similarity and spatial proximity. The autocorrelation coefficient, $r$, is a measure of genetic similarity between individuals that fall within a defined distance class and is closely related to Moran's-I, a weighted correlation coefficient used to detect departures from spatial randomness. In cases of positive genetic structure, the first $x$-intercept in the autocorrelogram ( $r$ plotted as a function of distance, where $r=0$ ) provides an index of the spatial extent of nonrandom (positive) genetic structure (Peakall et al. 2003). Individual pairwise genetic and geographical distance matrices derived from the data were used to calculate $r$ for different distance classes. The statistical significance of $r$ was determined by random permutation of all individuals among distance classes and computing the null distribution for $r$ in cases of no genetic structure. One thousand permutations were used to set the lower and upper $95 \%$ confidence limits for the populations in the dataset. Ninety-five percent confidence intervals were also calculated around each $r$ value by bootstrapping $r$ values within each distance class 1,000 times. Following Peakall et al. (2003), the null hypothesis of no spatial autocorrelation was rejected only when $r$ exceeded the $95 \% \mathrm{Cl}$ derived from the among-population permutation test, and when the $95 \% \mathrm{Cl}$ about $r$ (derived from bootstrapping) did not intercept the axis of $r=0$.

\section{Habitat suitability analysis}

Presence data of fireweed populations were obtained from two sources; from Hawaii Ecosystems at Risk (http://www.hear.org) and field collection data from this study. A total of 115 presence localities, five climatic and three categorical Geographical Information System (GIS) layers were used to develop a habitat suitability model. GIS layers consisted of: average annual precipitation (Daly and Halbleib 2006a), average annual maximum temperature, average annual minimum temperature (Daly and Halbleib 2006b), solar radiation in $\mathrm{Cal} / \mathrm{m}^{2} /$ day (Hawaii Statewide GIS Program: http://hawaii.gov/dbedt/gis/), major land resource areas (Waltman et al. 2002), land cover (EPA 1998), land use (NOAA 2000) and USGS $10 \mathrm{~m}$ digital elevation models (NOAA, NOS, NOAA/Biogeography Program 2001). All layers were visualized and analyzed within ArcMap software version 9.2.

An empirical model of habitat suitability was developed using the positive location data and the Weights of Evidence (WOE) GIS approach (Lenton et al. 2000; Bonham-Carter 1994; Guisan and Zimmermann 2000; Clevenger et al. 2002; Lenton et al. 2000). The WOE approach compares sets of known locations (response variables) to a prior distribution estimated by evidential themes (layers composed of quantitative and categorical data) theoretically influencing the ecology of the organism of interest (Bonham-Carter 1994; Lenton et al. 2000; Lyford et al. 2003). The approach has a form similar to regression (Bonham-Carter 1994). Weights indicative of the significance of autocorrelation between the evidential theme and the response variable were assigned to the classes within each evidential theme using the Spatial Analyst (ESRI) and the Hawthorn Analysis Tools version 3.26 extensions in ArcMap (Beyer 2006). The normality of the distribution was tested using SigmaStat Version 9.0 and the differential association of each locality was clumped into three to five weight classifications based on the distribution of localities and the evidential theme they were associated with. Classes within each theme map were reclassified using the weighted linear combination approach. Given that no inference as to the influence of one map layer over the other was made, the reclassified maps were summed equally using the Raster Math commands in ArcMap. The final output was a set of three predictive maps of the main Hawaiian Islands. Each map shows the influence of the various climatic, topographic and habitat-related variables in determining the distribution of fireweed. 


\section{Results}

\section{Within-population patterns of genetic diversity}

The microsatellite loci used in this study were polymorphic across populations sampled. The number of alleles per locus ranged from 19 (locus Se-194) to 46 (locus Se-136); within populations the mean number of alleles ranged from 4.8 to 12.9 (mean $=9.1$, Table 1 ). Expected heterozygosity ranged from 0.72 to 0.84 (mean $=0.79$ ) and observed heterozygosity from 0.34 to 0.53 (mean $=0.43$ ) across all loci. Overall, most Hawaii populations showed a deficit of heterozygotes from that expected under HWE, with some loci (Se220, Se-176(a) and Se-116) conforming to HWE proportions across the majority of populations. No linkage disequilibrium was detected among any of the eight loci across all populations.

\section{Population structure}

The majority of microsatellite diversity $(93.72 \%)$ resided within populations, with smaller, yet significant, amounts of diversity between islands (1.99\%) and among populations within islands (4.3\%) (Table 2). Overall, pairwise $F_{S T}$ values were moderate $\left(0.05 \leq F_{S T} \leq 0.15\right)$ ranging from 0.0002 to 0.18 , and regressions of $\log \left(F_{S T}\right)$ over log (geographical distances) were significant (Mantel test, $\left.r^{2}=0.151, P<0.001\right)$ (Fig. 2). When analyzed separately, both Hawaii and Maui retained a pattern of significant isolation by distance (results not shown).

Table 2

Results of hierarchical AMOVA comparing genetic variation within populations, among populations, and among islands of invasive Senecio madagascariensis

\begin{tabular}{|l|l|l|l|l|l|}
\hline Source of variation & d.f. & $\begin{array}{l}\text { Sum of } \\
\text { squares }\end{array}$ & $\begin{array}{l}\text { Fixation } \\
\text { index }\end{array}$ & $\begin{array}{l}\text { Percent } \\
\text { variation }\end{array}$ & $\begin{array}{l}\text { P- } \\
\text { value }\end{array}$ \\
\hline Among Islands & 1 & 45.131 & $\Phi_{\text {ct }}=0.06276$ & 1.99 & $<0.001$ \\
\hline $\begin{array}{l}\text { Among populations within } \\
\text { islands }\end{array}$ & 24 & 253.654 & $\Phi_{\text {sc }}=0.04378$ & 4.29 & $<0.001$ \\
\hline Within populations & 1362 & 4185.770 & $\Phi_{\text {st }}=0.01985$ & 93.72 & $<0.001$ \\
\hline
\end{tabular}

Significance was tested against a null distribution of 10,000 random permutations. Significant $P$ values are indicated with an asterisk 


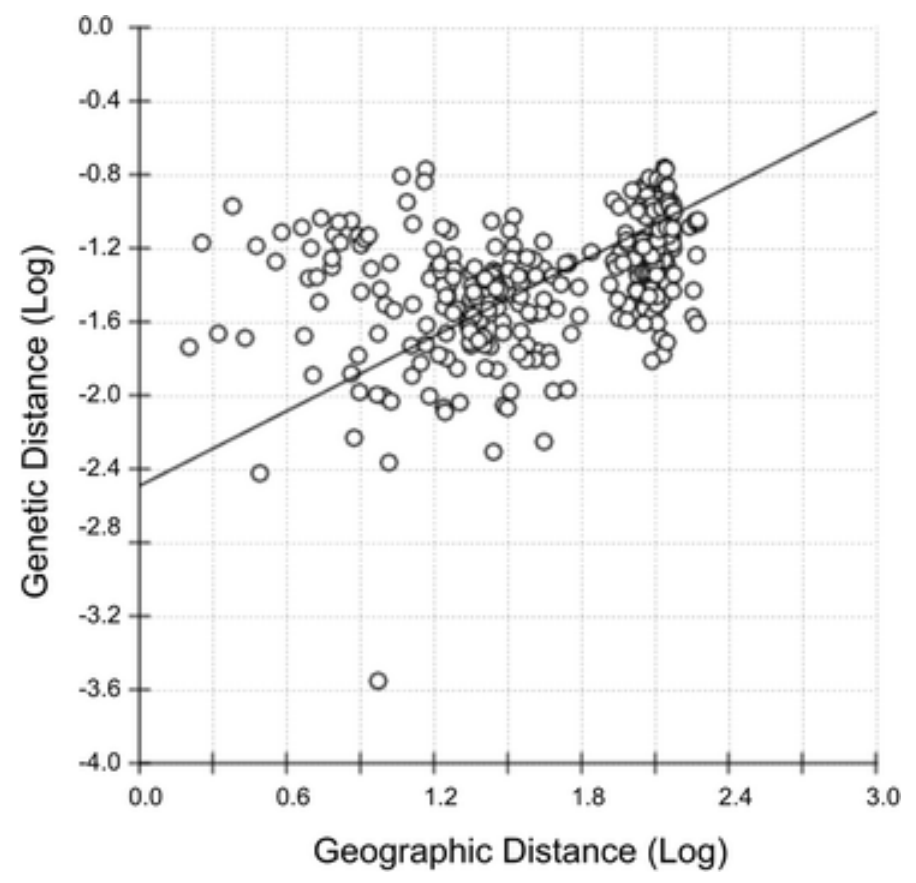

Fig. 2

Relationship between log transformed geographical and genetic distance (log $\left.\mathrm{F}_{\text {ST }}\right)$ among all populations of Senecio madagascariensis included in this study. Regression: $y=0.6780 x-2.493 ; r^{2}=0.151$

Following the method of Evanno et al. (2005), the model-based clustering method implemented in STRUCTURE (Falush et al. 2007) found two distinct major genetic clusters (K) that corresponded to the two islands of Maui and Hawaii (Fig. 3, also see Fig. S1). With the exception of individuals from population Haw1, the majority individuals were probabilistically correctly assigned to their island of origin (Hawaii, 92.6\% and Maui, 93.5\%; Fig. 3). Population Haw1 was collected in southern part of Hawaii, where fireweed was historically not known to occur and had $\sim 80.0 \%$ of its individuals assigned to the Maui deme. Separate analysis of each major genetic deme identified three distinct genetic subgroups within each (Fig. 3). Except for population Mau7, all populations from the Maui deme belonged to only one of the three potential subgroups (Figs. 1, 3). Haw 1 shared the same genetic subgroup with populations from central Maui. In the Hawaii deme genetic subgroups were dispersed throughout most populations, with the exception of four populations on the south western and southern slopes of Mauna Kea (Haw15, 16, 17 and 18). The majority of individuals within these populations belonged to a single genetic subgroup (i.e. $\geq 50 \%$ of individuals). 


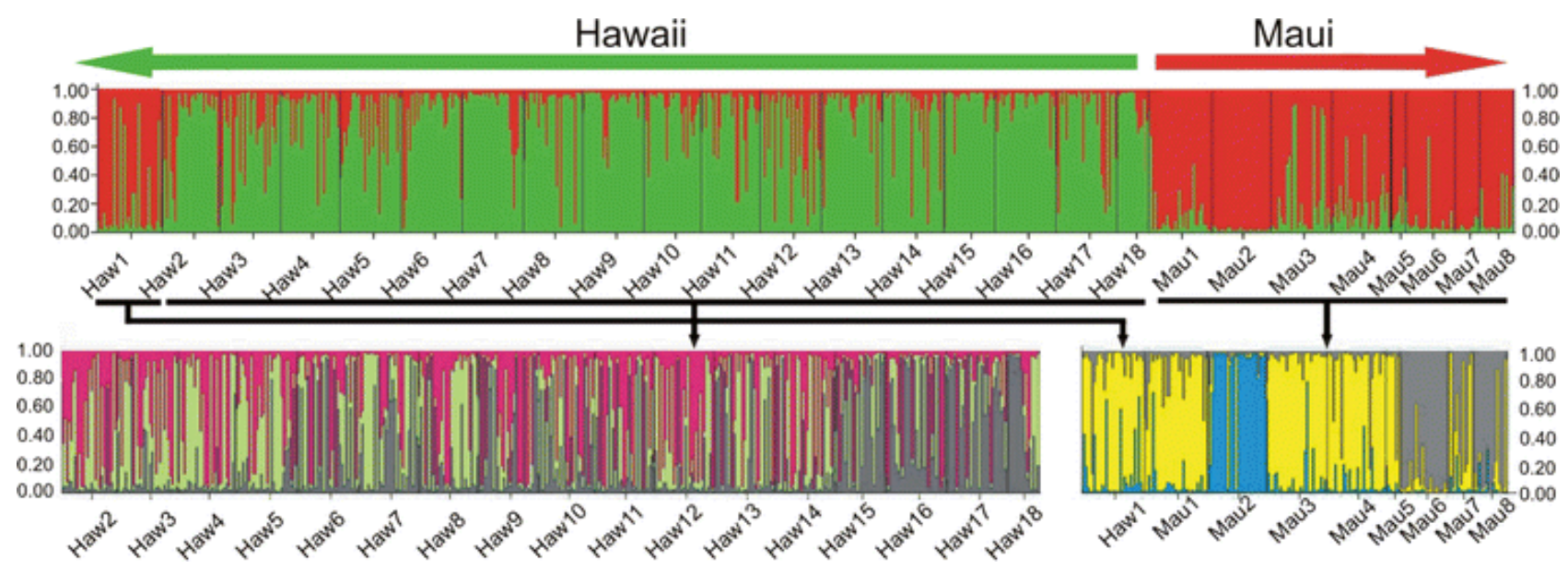

Fig. 3

Population structure inferred by Bayesian assignment of 694 Hawaiian individuals of Senecio madagascariensis shown as individual membership coefficients in the STRUCTURE-identified major genetic demes (top). Fireweed individuals in the archipelago can be assigned to two geographical genetic demes that corresponded to two islands (Maui and Hawaii), each represented by a cluster of populations. Population Haw1 was the only population with its individuals not clustering within the 'correct' deme. Three subgenetic groups (bottom) were also identified within each major genetic deme. Spatial relationships amongst these are illustrated in Fig. 1

Contemporary estimates of dispersal in GeneClass2 (Piry et al. 2004) identified 57 out of 694 individuals as potential 'first generation migrants' $(P<0.01)$. However, given the low genetic structure among pairwise populations found here $\left(0.0002 \leq F_{S T} \leq 0.18\right)$, results based on the identification of immigrants should be interpreted with caution since a decrease in genetic differentiation decreases the ability to correctly identify immigrants. We therefore only focused on overall patterns of 'potential migration'. Not surprisingly, the majority of migrants were identified within islands (81.0\%) with the rest identified as among-island migrants. Migration was thus also strongly correlated with geographical distance between putative donor and recipient populations with $54.0 \%$ of all potential migrants found within $25 \mathrm{~km}$ from their putative sources (Fig. 4). In concordance with the STRUCTURE results, the majority of potentially longdistance dispersers ( $>100 \mathrm{~km}$ ) were individuals from the Hawaii population Haw1 and populations from central Maui (Mau2 and Mau3). In addition, other potential inter-island dispersers were identified between populations Haw11 and Mau1, Haw15 and Mau4, Mau5 and Haw12, and Mau3 and Haw6.

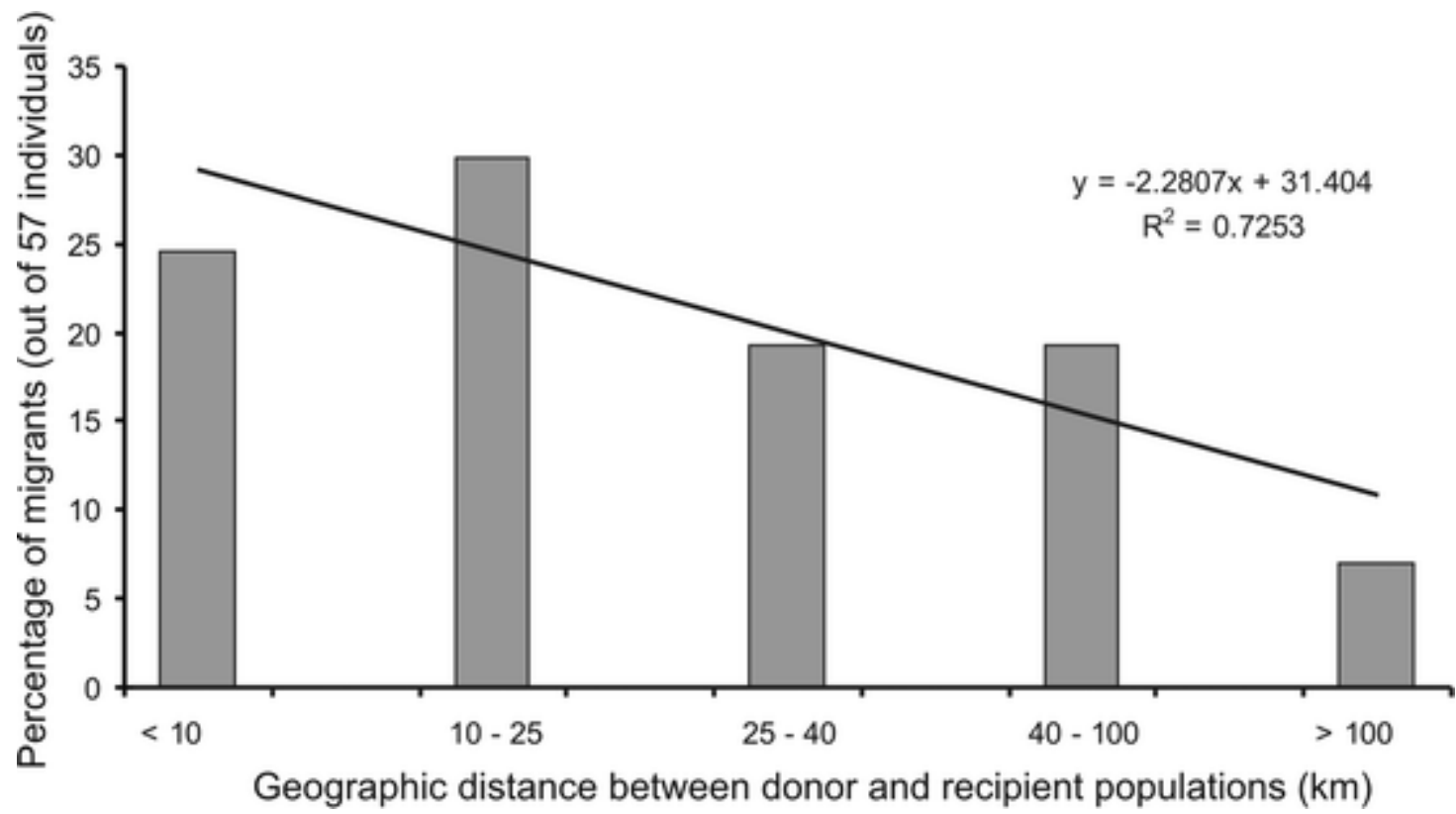




\section{Fig. 4}

Bar plot indicating the relationship between the incidence of potential 'first generation migration' as identified in GeneClass2 (Piry et al. 2004) and geographic distance between donor and recipient populations

\section{Table 3}

Statistical comparison of allelic richness $\left(R_{s}\right)$, unbiased gene diversity $\left(H_{s}\right)$, observed heterozygosity $\left(H_{o}\right)$, inbreeding coefficient $\left(F_{I S}\right)$ and levels of differentiation among populations $\left(F_{S T}\right)$, for the two invaded Hawaiian Islands, Hawaii and Maui, of Senecio madagascariensis

\begin{tabular}{|l|l|l|l|l|l|}
\hline & $\left(\mathbf{R}_{\mathbf{S}}\right)$ & $\left(\mathbf{H}_{\mathbf{S}}\right)$ & $\left(\mathbf{H}_{\mathbf{~}}\right)^{* * *}$ & $\left.\mathbf{( F}_{\text {IS }}\right)^{* *}$ & $\left(\mathbf{F}_{\mathbf{~ S T}}\right)^{*}$ \\
\hline Hawaii & 4.556 & 0.759 & 0.457 & 0.398 & 0.029 \\
\hline Maui & 4.291 & 0.749 & 0.527 & 0.296 & 0.074 \\
\hline
\end{tabular}

$* \mathrm{P}<0.05, * * \mathrm{P}<0.001$

\section{Spatial autocorrelation analysis}

Across fireweed populations, the autocorrelogram showed significant positive genetic correlations among geographically close populations followed by an overall clinal pattern of genetic structure (Fig. $\underline{5}$ ). At smaller spatial scales ( $1 \mathrm{~km}$ intervals) the genetic patch associated with high positive spatial correlation (within $9 \mathrm{~km})$ revealed that genetic correlation increased between $1 \mathrm{~km}(r=0.059)$ to $2 \mathrm{~km}(r=0.067)$ and then drops drastically at $3 \mathrm{~km}(r=0.021)$, however, $r$ fluctuated, being positive at distances greater than $9 \mathrm{~km}$.

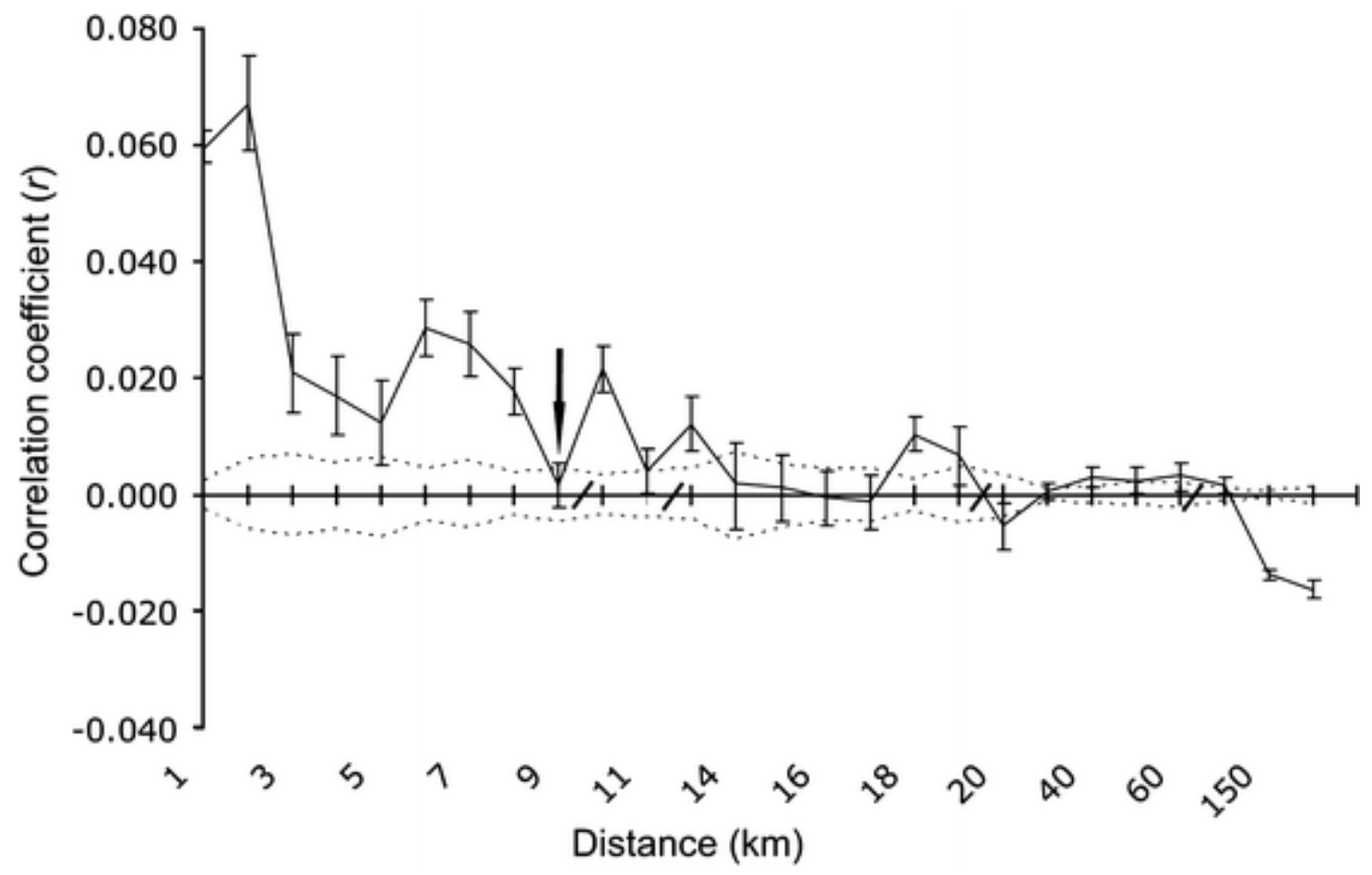

Fig. 5

Autocorrelogram of the spatial coefficient, $r$, as a function of distance. The null hypothesis of no spatial genetic structure is bounded by the $95 \%$ confidence intervals (dashed lines) derived from randomly permuting individual genotypes over geographical locations. Error bars for mean $r$ at each distance class were estimated with bootstrapping. The distance scale where positive spatial autocorrelation ceases is indicated by the arrow 


\section{Habitat suitability}

For climate data, the WOE GIS approach identified areas on all five major Hawaiian Islands suitable for fireweed invasion (Fig. $6 \mathrm{a}-\mathrm{C}$ ). Particularly suitable are low elevation and arid areas on the windward sides of all islands, with minimum and maximum annual temperatures between $12-18^{\circ} \mathrm{C}$ and $21.2-26.5^{\circ} \mathrm{C}$ respectively, elevations between sea level and $1,000 \mathrm{~m}$, solar radiation levels between $350-400$ calories $/ \mathrm{m}^{2} /$ day, and annual precipitation between 178-376 mm/year (Fig. 6a). When land cover, land use and major land resource areas were considered, suitable habitats were associated with urban areas, shrub land, range, and pasture lands respectively (Fig. 6b). Similarly, the combined climatological and categorical dataset also identified low-lying coastal areas as most suitable habitats for fireweed invasions (Fig. 6c).

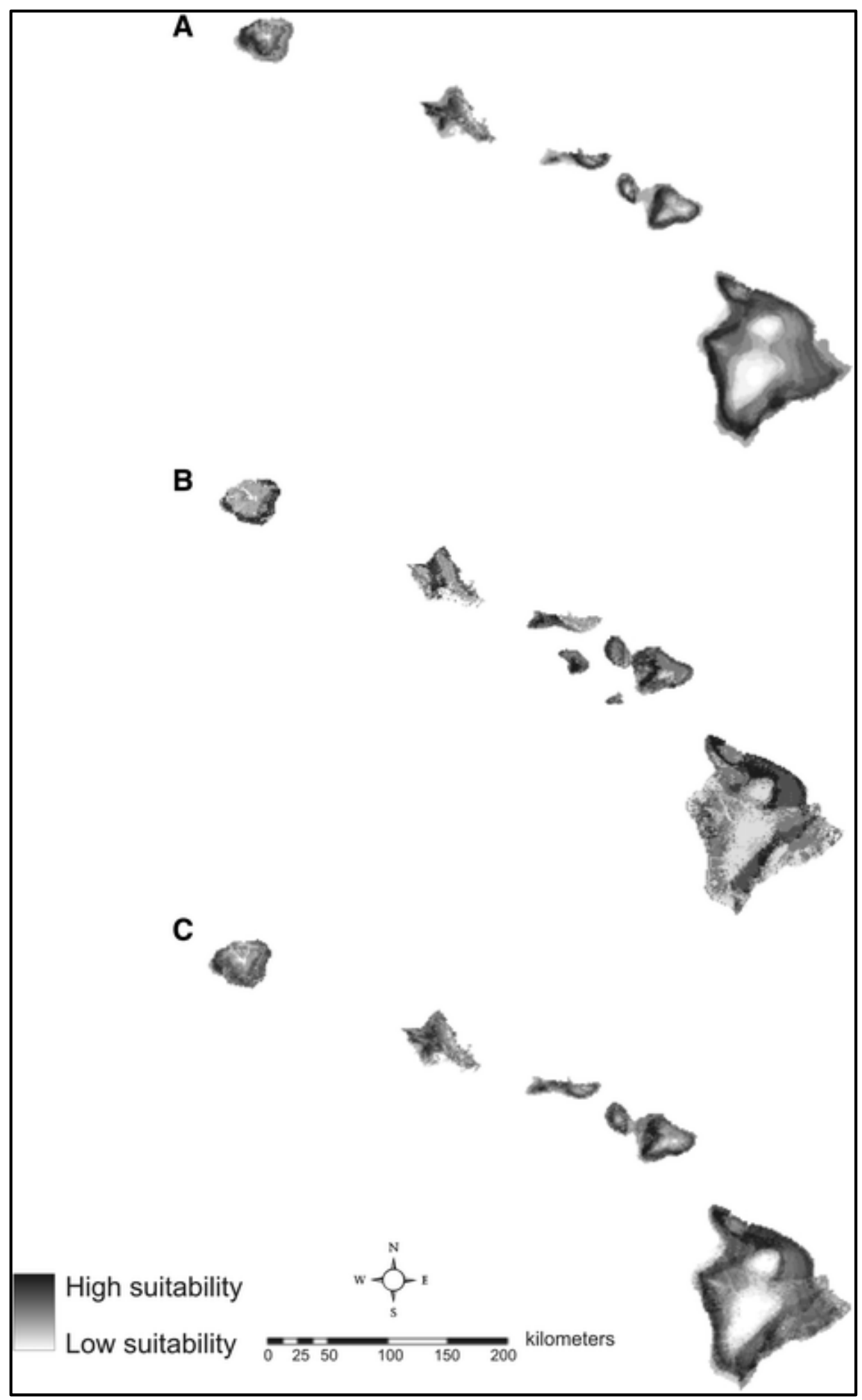




\section{Fig. 6}

Habitat suitability maps constructed using the Weights of Evidence for climatological (precipitation, min and max temperatures, elevation, solar radiation [6A]) and three categorical (Land use, land cover and major land resource areas [6B]) and the combined (6C) datasets. Highly suitable habitat is indicated as dark (black) shaded areas, intermediately suitable as grey shaded areas and unsuitable as light (white)

\section{Discussion}

According to population genetics theory, high genetic diversity should benefit invasive species by facilitating adaptation in their new environments. However, colonization is often accompanied by lowered genetic variation due to founder events and because some species are self-compatible or use strategies such as clonal growth or apomixy (Novak and Welfley 1997; Amsellem et al. 2000). Not surprisingly, lowered genetic diversities and high levels of inbreeding are commonly reported for many introduced species (e.g. Bjorkland and Baker 1996; Neuffer and Hurka 1999; Young and Murray 2000). However, others have shown, using historical and molecular data, that many invasive plants possess significant genetic diversities in their invasive ranges (e.g. Phalaris arundinacea, Lavergne and Molofsky 2007; Alliaria petiolata, Durka et al. 2005; Euphorbia esula, Rowe et al. 1997), likely as a result of multiple introductions. Despite the observed genetic diversity, fireweed in the Hawaiian Islands shows moderate levels of inbreeding. It remains unclear whether this reflects a founder effect or species-specific phenomenon. Inbreeding may be an indirect consequence of mating between close relatives (non-random mating) due to small founder population sizes and/or excessive selfing. Anecdotal evidence suggests that fireweed is selfcompatible under field conditions (Curt Daehler, personal communication). Given available genetic variation, the elevated levels of inbreeding found here provide some evidence for extensive selfing in the field. This is also in agreement with Ernst (1998) who illustrated that fireweed's closest relative within the species complex, $\mathrm{S}$. inaequidens, is highly self-compatible.

It is thought that fireweed represents a single secondary introduction from Australia that reached Hawaii via the importation of contaminated animal feed (Motooka et al. 1999). Extensive agricultural trade between Hawaii and Australia during the early 1980's could have facilitated its introduction. No trade occurred between Hawaii and any of fireweed's native range countries prior to its introduction to the islands. DNA sequence data confirmed that Hawaiian and Australian fireweed share the same ITS haplotype, which is closely related to, but not exactly the same as, haplotypes from the native range in eastern South Africa (Le Roux et al. 2006; Scott et al. 1998).

Previous studies suggest that fireweed was first introduced to the island of Hawaii, from where it spread to Maui (Motooka et al. 1999; Gardner et al. 2006). It is thus possible that a single introduction event occurred to the Hawaiian Islands and that, as a result of drift and isolation, genetic differentiation as was found here, accrued over time. Expectations under this scenario include a subset of shared alleles and low genetic uniqueness (private alleles) among donor and recipient islands. However, allelic distributions showed that each island harboured a large proportion of private alleles ( 22\%). Also, Maui and Hawaii differed significantly in the amount of heterozygosity $\left(\mathrm{H}_{\mathrm{O}}\right)$, inbreeding $\left(\mathrm{F}_{\mathrm{IS}}\right)$ and levels of differentiation among populations $\left(\mathrm{F}_{\mathrm{ST}}\right)$. Mean observed heterozygosity was, on average, $7.0 \%$ higher in Maui than in Hawaii. Again, spread from Hawaii to Maui would have had the opposite effect, decreasing heterozygosity in the direction of long-distance dispersal. Rather, the single Hawaii population, Haw1, seemed to have been introduced from central Maui to Hawaii. In addition, assignment of individuals as potential 'first generation migrants' between different islands indicated that inter-island dispersal may occur at low frequency. Overall, we postulate that the two genetically distinct and island-specific clusters identified represent at least two separate introduction events from Australia: one to Hawaii in the early 1980's followed by another introduction substantially later to Maui (Gardner et al. 2006). However, the genetic subgroups found within each major genetic deme also renders support for the hypothesis that more than two introductions may have occurred to each island independently during this time.

Despite the recent introduction of fireweed to the Hawaiian Islands, it has rapidly dispersed and established over large areas. Similarly, Sindel and Michael (1988) reported that fireweed-infested farmlands in New South Wales, Australia, increased exponentially following its introduction. The hairy pappus of fireweed may be caught up in wind more easily than other anemochorous Senecio species (Sindel et al. 1998). This, coupled with seed production of up to 18,000 seeds per individual and high frequency of strong trade winds in the Hawaiian Islands, contributes to fireweed's rapid dispersal within the islands. Thus, together with the strong correlation between genetic similarity and geographic proximity over smaller 
spatial scales, it appears that fireweed disperses via a stratified approach. Rare events such as human-, animal- and vehicle-aided extreme long-distance dispersal (Wilson et al. 2009) could lead to the establishment of outlying foci that can act as new sources for diffusive spread. Indeed, while results should be interpreted with caution, partial Bayesian analysis identified 57 potential 'first generation migrants'. While most of these corresponded to within island dispersers the strongest evidence for a rare extreme long-distance dispersal event come from the southern Hawaii population, Haw1, which likely originated from central Maui. For stratified dispersal eradication of small pioneering populations in front of a continuous invasion front can be the most effective means of slowing or even stopping spread (Moody and Mack 1988). Small founding populations of fireweed have been successfully eradicated on the island of Oahu (M. Ramadan, personal communication).

However, dispersal alone is not a reliable indicator of potential range expansions (Hulme 2003) as dispersed propagules also need to encounter favorable/suitable habitat. Suitable areas for fireweed invasion identified here are likely conservative as our data relied on presence data and, if fireweed has not reached its true range limits yet, would be underestimated. Nevertheless, these estimates show that all major Hawaiian Islands are suitable for fireweed invasion, especially drier, coastal areas. Since our models did not consider the mechanisms and pathways responsible for the species' dispersal, it is also important to note that these results are by no means a guarantee that fireweed will definitely be found in, or spread into, suitable areas. They only provide an indication that the combination of the climatic and habitat factors present in that location are likely suitable for the species.

The question remains then why fireweed only occurs on two of the Hawaiian Islands even though it has the potential to spread to other islands. One potential explanation is the differential intensity of livestock farming among the main islands, which may have led to disproportional distribution of animal fodder contaminated with fireweed seeds. Indeed, the heavily fireweed-infested Maui and Hawaii harbour $80.0 \%$ of the state's livestock farms (National Agricultural Statistics Service, USDA). This would also have maximized opportunities for past exchange (long-distance dispersal) between these two islands. However, given the extent of suitable area for fireweed invasion, and the capacity of the species to disperse within and between islands, our results emphasize the need for strict quarantine regulations when animal fodder, soil, and other agricultural products are transported from Hawaii and Maui to currently-uninfested areas or to neighbouring islands. Such screening measures are essential steps towards the implementation of effective early detection and eradication programmes to prevent the establishment of the Senecio madagascariensis on currently uninfested islands. 


\section{References}

- Amsellem L, Noyer JL, Le Bourgeois T, Hossaert-McKey M (2000) Comparison of genetic diversity of the invasive weed Rubus alceifolius Poir. (Rosaceae) in its native range and in areas of introduction, using amplified fragment length polymorphism (AFLP) markers. Mol Ecol 9:443-455

- Barrett SCH, Colautti RI, Eckert CG (2008) Reproductive systems and evolution during biological invasion. Mol Ecol 17:373-383

- Beyer H (2006) Hawths analysis tools for ArcGIS, p. Spatial Ecology toolset extension for ArcGIS. Available at http://www.spatialecology.com/htools

- Bjorkland MJ, Baker AJ (1996) The successful founder: genetics of introduced Carduelis chloris (greenfinch) populations in New Zealand. Heredity 77:410-422

- Bonham-Carter GF (1994) Geographic information systems for geoscientists: modelling with GIS. Pergamon, Oxford

- Clevenger APJ, Wierzchowski J, Chruszcz B, Gunson K (2002) GIS-generated, expert-based models for identifying wildlife habitat linkages and planning mitigation passages. Conserv Biol 16:503-514

- Coulon A, Fitzpatrick JW, Bowman R, Stith BM, Makarewich CA, Stenzler LM, Lovette IJ (2008) Congruent population structure inferred from dispersal behaviour and intensive genetic surveys of the threatened Florida scrub-jay (Aphelocoma coerulescens). Mol Ecol 17:1685-1701

- Daly C, Halbleib M (2006) Pacifc Islands (Hawaii) average monthly and annual precipitation, 19712000 p. Raster digital format. The PRISM Group at Oregon State University, Corvallis, Oregon, USA

- Daly C, Halbleib M (2006) Pacifc Islands (Hawaii) average monthly and annual minimum and maximum temperature and mean dewpoint temperature, 1971-2000 p. Raster digital format. The PRISM Group at Oregon State University, Corvallis, Oregon, USA

- Durka W, Bossdorf O, Prati D, Auge H (2005) Molecular evidence for multiple introductions of garlic mustard (Alliaria petiolata, Brassicaceae) to North America. Mol Ecol 14:1697-1706

- EPA (1998) Land use and landcover of main Hawaiian Islands as of 1976, p. 1976 Digital GIRAS (Geographic information retrieval and analysis) files. State of Hawaii

- Ernst WHO (1998) Invasion, dispersal and ecology of the South African neophyte Senecio inaequidens in The Netherlands: from wool alien to railway and road alien. Acta Bot Neerl 47:131151

- Evanno G, Regnaut S, Goudet J (2005) Detecting the number of clusters of individuals using the software STRUCTURE: a simulation study. Mol Ecol 14:2611-2620

- Excoffier L, Smouse PE, Quattro JM (1992) Analysis of molecular variance inferred from metric distances amomng DNA haplotypes: application to human mitochondrial DNA restriction data. Genetics 131:479-491

- Falush D, Stephens M, Pritchard JK (2007) Inference of population structure using multilocus genotype data: dominant markers and null alleles. Mol Ecol Notes 7:574-578

- Gardner DR, Thorne MS, Molyneux RJ, Pfister JA, Seawright AA (2006) Pyrrolizidine alkaloids in Senecio madagascariensis from Australia and Hawaii and assessment of possible livestock poisoning. Biochem Syst Ecol 34:736-744Goolsby JA, De Barro PJ, Makinson JR, Pemberton RW, Hartley DM, Frohlicj DR (2006) Matching the origin of an invasive weed for the selection of a herbivore haplotype for a biological control programme. Mol Ecol 16:287-297

- Goudet J (2001) FSTAT, a program to estimate and test gene diversities and fixation indices version 2.9.3. Available from http://www.unil.ch/izea/softwares/fstat.html

- Guisan A, Zimmermann NE (2000) Predictive habitat distribution models in ecology. Ecol Model 135:147-186

- Guo SW, Thompson EA (1992) A monte carlo method for combined segregation and linkage analysis. Am J Hum Genet 51:1111-1126

- Hawaii Statewide GIS Program, Office of Planning, Department of Business, Economic Development \& Tourism, Honolulu, Hawaii, USA. Available at http://hawaii.gov/dbedt/gis/

- Hulme PE (2003) Biological invasions: winning the science battles but losing the conservation war? Oryx 37:178-193

- Jensen JL, Bohonak AJ, Kelley ST (2005) Isolation by distance, web service. BMC Genetics 6: 13. v.3.15 http://ibdws.sdsu.edu/ 
- Keane RM, Crawley MJ (2002) Exotic plant invasions and the enemy release hypothesis. Trends Ecol Evol 17:164-170

- Kearney MR, Porter WP (2009) Mechanistic niche modelling: combining physiological and spatial data to predict species' ranges. Ecol Lett 12:334-350

- Lafuma L, Maurice S (2007) Increase in mate availability without loss of self-incompatibility in the invasive species Senecio inaequidens (Asteraceae). Oikos 116:201-208

- Lavergne S, Molofsky J (2007) Increased genetic diversity and evolutionary potential drive the success of an invasive grass. Proc Natl Acad Sci USA 104:3883-3888

- Le Roux JJ, Wieczorek AM (2006) Isolation and characterization of polymorphic microsatellite markers from fireweed, Senecio madagascariensis Poir. (Asteraceae). Mol Ecol Notes 7:327-329

- Le Roux J, Wieczorek AM (2009) Molecular systematics and population genetics of biological invasions: towards a better understanding of invasive species management. Ann Appl Biol 154:1-17

- Le Roux JJ, Wieczorek AM, Ramadan MM, Tran CT (2006) The native provenance of invasive fireweed (Senecio madagascariensis Poir.) in the Hawaiian Islands as inferred from phylogenetic analysis. Divers Distrib 12:694-702

- Lee CE (2002) Evolutionary genetics of invasive species. Trends Ecol Evol 17:386-391

- Lenton SM, Fa JE, Perez Del Val J (2000) A simple non-parametric GIS model for predicting species distribution: endemic birds in Bioko Island, West Africa. Biodivers Conserv 9:869-885

- Lyford ME, Jackson ST, Betancourt JL, Gray ST (2003) Influence of landscape structure and climate variability on a late Holocene plant migration. Ecol Monogr 73:567-583

- Moody ME, Mack RN (1988) Controlling the spread of plant invasions: the importance of nascent foci. J Appl Ecol 25:1009-1021

- Mooney HA, Cleland EE (2001) The evolutionary impact of invasive species. Proc Natl Acad Sci USA 98:5446-5451

- Motooka P, Nagai G, Onuma K, DuPonte M, Kawabata A, Fukumoto G (1999) Control of fireweed (Senecio madagascariensis).CTAHR Publication on Weed Control WC-2. University of Hawaii Press, Honolulu

- Neuffer B, Hurka H (1999) Colonization history and introduction dynamics of Capsella bursapastoris (Brassicaceae) in North America: isozymes and quantitative traits. Mol Ecol 8:1667-1681

- NOAA (2000) Main eight Hawaiian islands land cover. National Oceanic and Atmospheric Administration, Coastal Services Center NOAA Coastal Services Center, Charleston, South Carolina

- NOAA, NOS, NOAA/Biogeography Program (2001) Digital elevation models main Hawaiian Islands, National Oceanic and Atmospheric Administration, Center for Coastal Monitoring and Assessment, Silver Spring, Maryland

- Novak SJ, Welfley AY (1997) Genetic diversity in the introduced clonal grass Poa bulbosa (Bulbous bluegrass). Northwest Sci 71:271-280

- Paetkau D, Slade R, Burden M, Estoup A (2004) Direct, real-time estimation of migration rate using assignment methods: a simulation-based exploration of accuracy and power. Mol Ecol 13:55-65

- Peakall R, Smouse PE (2006) GENALEX 6: genetic analysis in Excel. Population genetic software for teaching and research. Mol Ecol Notes 6:288-295

- Peakall R, Ruibal M, Lindenmayer DB (2003) Spatial autocorrelation analysis offers new insights into gene flow in the Australian bush rat, Rattus fuscipes. Evolution 57:1182-1195

- Piry S, Alapetite A, Cornuet J-M, Paetkau D, Baudouin L, Estoup A (2004) GeneClass2: a software for genetic assignment and first-generation migrant detection. J Hered 95:536-539

- Pritchard JK, Stephens M, Donnelly P (2000) Inference of population structure using multilocus genotype data. Genetics 155:945-959

- Rannala B, Mountain JL (1997) Detecting immigration by using multilocus genotypes. Proc Natl Acad Sci USA 94:9197-9201

- Robertson BC, Gemmell NJ (2004) Defining eradication units in pest control programmes. J Appl Ecol 41:1042-1048

- Rosenthal DM, Ramakrishnan AP, Cruzan MB (2008) Evidence for multiple sources of invasion and intraspecific hybridization in Brachypodium sylvaticum (Hudson) Beauv. in North America. Mol Ecol 17:4657-4669 
- Rowe ML, Lee DJ, Nissen SJ, Bowditch BM, Masters RA (1997) Genetic variation in North American leafy spurge (Euphorbia esula) determined by DNA markers. Weed Sci 45:446-454

- Sakai AK, Weller SG, Allendorf FW, Holt JS, Lodge DM, Molofsky J et al (2001) The population biology of invasive species. Annu Rev Ecol Syst 32:305-332

- Schneider S, Roessli D, Excoffier L (2000) ARLEQUIN Version 2.000: a software for population genetic data analysis. Genetics and Biometry Laboratory, University of Geneva, Switzerland

- Scott LJ, Congdon BC, Playford J (1998) Molecular evidence that fireweed (Senecio madagascariensis, Asteraceae) is of South African origin. Plant Syst Evol 213:251-257

- Sindel BM, Michael PW (1988) Survey of the impact and control of fireweed (Senecio madagascariensis Poir.) in New South Wales. Plant Prot Q 13:22-28

- Sindel BM, Radford IJ, Holtkamp RH, Michael PW (1998) Senecio madagascariensis Poir. The biology of Australian weeds. 33. Plant Prot Q 13:2-15

- Smouse PE, Peakall R (1999) Spatial autocorrelation analysis of individual multi-allele and multilocus genetic structure. Heredity 82:561-573

- Strauss SY, Lau JA, Carroll SP (2006) Evolutionary responses of natives to introduced species: what do introductions tell us about natural communities? Ecol Lett 9:354-371

- van Kleunen M, Fischer M, Johnson SD (2007) Reproductive assurance through self-fertilization does not vary with population size in the alien invasive plant Datura stramonium. Oikos 116:14001412

- Viard F, Ellien C, Dupont L (2006) Dispersal ability and invasion success of Crepidula fornicata in a single gulf: insights from genetic markers and larval-dispersal model. Helgol Mar Res 60:144-152

- Vitousek PM (1990) Biological invasions and ecosystem processes: towards an integration of population biology and ecosystem studies. Oikos 57:7-13

- Waltman S, Grantham K, Oman D, Muehlbach G (2002) Major land resource areas, p. Major Land Resource Areas for the main hawaiian islands. US Department of Agriculture (USDA) and Natural Resources Conservation Service (NRCS)

- Wilson JRU, Dormontt EE, Prentis PJ, Lowe AJ, Richardson DM (2009) Something in the way you move: dispersal pathways affect invasion success. Trends Ecol Evol 24:136-144

- Wright S (1965) The interpretation of population structure by F-statistics with special regard to systems of mating. Evolution 19:395-420

- Young AG, Murray BG (2000) Genetic bottlenecks and dysgenic gene flow into re-established populations of the grassland daisy, Rutidosis leptorrhynhoides. Aust J Bot 43:409-416 